\title{
The Antibacterial Assay of Tectorigenin with Detergents or ATPase Inhibitors against Methicillin-Resistant Staphylococcus aureus
}

\author{
Dae-Ki Joung, ${ }^{1}$ Su-Hyun Mun, ${ }^{2}$ Kuang-Shim Lee, ${ }^{3}$ Ok-Hwa Kang, ${ }^{1}$ Jang-Gi Choi, ${ }^{1}$ \\ Sung-Bae Kim, ${ }^{2}$ Ryong Gong, ${ }^{2}$ Myong-Soo Chong, ${ }^{3}$ Youn-Chul Kim, ${ }^{4}$ Dong-Sung Lee, ${ }^{4}$ \\ Dong-Won Shin, ${ }^{5}$ and Dong-Yeul Kwon ${ }^{1,2}$ \\ ${ }^{1}$ Department of Oriental Pharmacy, College of Pharmacy and Wonkwang-Oriental Medicines Research Institute, \\ Wonkwang University, Iksan, Jeonbuk 570-749, Republic of Korea \\ ${ }^{2}$ BK21 Plus Team, Professional Graduate School of Oriental Medicine, Wonkwang University, Iksan, \\ Jeonbuk 570-749, Republic of Korea \\ ${ }^{3}$ Department of Third Medicine, Professional Graduate School of Oriental Medicine, Wonkwang University, Iksan, \\ Jeonbuk 570-749, Republic of Korea \\ ${ }^{4}$ Standardized Material Bank for New Botanical Drugs, College of Pharmacy, Wonkwang University, Iksan, \\ Jeonbuk 570-749, Republic of Korea \\ ${ }^{5}$ Department of Oriental Medicine Resources, Sunchon National University, Jeonnam 540-742, Republic of Korea
}

Correspondence should be addressed to Dong-Yeul Kwon; sssimi@wku.ac.kr

Received 12 February 2014; Revised 22 April 2014; Accepted 29 April 2014; Published 28 May 2014

Academic Editor: José Luis Ríos

Copyright (C) 2014 Dae-Ki Joung et al. This is an open access article distributed under the Creative Commons Attribution License, which permits unrestricted use, distribution, and reproduction in any medium, provided the original work is properly cited.

\begin{abstract}
Tectorigenin (TTR) is an O-methylated isoflavone derived from the rhizome of Belamacanda chinensis (L.) DC. It is known to perform a wide spectrum of biological activities such as antioxidant, anti-inflammatory, anti-tumor. The aim of this study is to examine the mechanism of antibacterial activity of TTR against methicillin-resistant Staphylococcus aureus (MRSA). The antiMRSA activity of TTR was analyzed in combination assays with detergent, ATPase inhibitors, and peptidoglycan (PGN) derived from S. aureus. Transmission electron microscopy (TEM) was used to monitor survival characteristics and changes in $S$. aureus morphology. The MIC values of TTR against all the tested strains were $125 \mu \mathrm{g} / \mathrm{mL}$. The OD(600) of each suspension treated with a combination of Triton X-100, DCCD, and $\mathrm{NaN}_{3}$ with TTR $(1 / 10 \times \mathrm{MIC})$ had been reduced from $68 \%$ to $80 \%$, compared to the TTR alone. At a concentration of $125 \mu \mathrm{g} / \mathrm{mL}$, PGN blocked antibacterial activity of TTR. This study indicates that anti-MRSA action of TTR is closely related to cytoplasmic membrane permeability and ABC transporter, and PGN at $125 \mu \mathrm{g} / \mathrm{mL}$ directly bind to and inhibit TTR at $62.5 \mu \mathrm{g} / \mathrm{mL}$. These results can be important indication in study on antimicrobial activity mechanism against multidrug resistant strains.
\end{abstract}

\section{Introduction}

Methicillin-resistant Staphylococcus aureus (MRSA) can lead to considerable morbidity and mortality in orthopaedic patients. The mortality rate from MRSA bacteraemia is double that of methicillin-sensitive Staphylococcus aureus (MSSA) [1]. The complication rate and cost of periprosthetic joint infection with MRSA is considerably higher compared to those of MSSA [2]. Patients receiving orthopaedic implants are most vulnerable, given the potential for biofilm formation and long-term morbidity $[3,4]$. Yet, the incidence of MRSA in orthopaedic patients has increased [5]. MRSA strains have become resistant not only to $\beta$-lactam antibiotics but also to fluoroquinolones and other families of antibiotics [6]. 
Tectorigenin (TTR), an O-methylated isoflavone, has been shown to possess antioxidant, anti-inflammatory, antitumor activities and has selective estrogen receptor modulator activities [7-10]. TTR significantly decreased in the concentration of DPPH radical on the scavenging ability of the tectorigenin, inhibited the IFN- $\gamma /$ LPS-induced NO, COX-2, PGE2, and IL-1 $\beta$ production in the activated macrophages RAW 264.7 cells, and caused a significant inhibition of tumor growth in LLC bearing C57BL/6 mice [11]. It showed the inhibitory effect of isoflavones isolated from the Pueraria thunbergiana (Leguminosae) against Helicobacter pylori [12]. In this study, we used TTR that isolated from rhizome of Belamcanda chinensis, it was called drug for eliminating sputum as well as clearing away heat and detoxicating [13]. TTR can be isolated from Pueraria thunbergiana, Belamcanda chinensis, or Pueraria lobata [14-16]. Although it has many biological activities, TTR has not yet been reported to have antibacterial activity on MRSA, multidrug-resistant pathogen.

In the present study, to clarify the mechanism of antiMRSA activity of TTR, we investigated the antibacterial activities of TTR on the membrane-binding agent and ATPase-inhibiting agents. In addition, we also investigated the effects of adding peptidoglycan (PGN) derived from $S$. aureus into Mueller-Hinton broth (MHB) that contained TTR alone. In this study, we aimed to gain insights into the antibacterial activity, survival characteristics, and changes in bacterial morphology and mechanism of TTR against MRSA.

\section{Materials and Methods}

2.1. Isolation and Purification of Tectorigenin. Tectorigenin $(>95 \%)$ was deposited at the Standardized Material Bank for New Botanical Drugs (number NNMBP000017) at Wonkwang University (Iksan, Republic of Korea). The dried rhizome of Belamcanda chinensis was purchased from the University Oriental Drugstore, Iksan, Korea, in June 2006 and was positively identified by Professor Youn-Chul Kim, College of Pharmacy, Wonkwang University. A voucher specimen (number WP06-189) was deposited at the Herbarium of the College of Pharmacy, Wonkwang University (Korea). The dried rhizome of $B$. chinensis $(1 \mathrm{~kg})$ was extracted twice with $70 \%$ aqueous EtOH ( $2 \mathrm{~L}$ ) under the ultrasonic condition for $3 \mathrm{~h}$. The $70 \% \mathrm{EtOH}$ extract ( $259 \mathrm{~g}$ ) was suspended in $\mathrm{H}_{2} \mathrm{O}$ (1L) and partitioned successively with $n$-hexane $(800 \mathrm{~mL}$ $\times 2)$ and $\mathrm{CHCl}_{3}(800 \mathrm{~mL} \times 2)$ to yield $n$-hexane soluble (7.71 g) and $\mathrm{CHCl}_{3}$-soluble extract $(41.94 \mathrm{~g})$. The $\mathrm{CHCl}_{3}$ soluble extract was subjected to column chromatography (CC) on silica gel, which was using $n$-hexane-EtOAc $(4: 1 \rightarrow$ $2: 1)$ to give four fractions (Fr. A-D). Fr. A (1.75 g) was subjected to silica gel $\mathrm{CC}$ with $\mathrm{CHCl}_{3}-\mathrm{MeOH}(25: 1)$ to get three subfractions (Fr. A1-A3). Fr. A2 (540 mg) was further chromatographed on a Sephadex $\mathrm{LH}-20$ with $\mathrm{CHCl}_{3}-\mathrm{MeOH}$ $(25: 1)$ to afford tectorigenin $(387 \mathrm{mg}, 0.0387 \mathrm{w} / \mathrm{w} \%)$. The structure of tectorigenin was identified by comparison of its ${ }^{1} \mathrm{H}$ - and ${ }^{13} \mathrm{C}$-NMR data with those reported in the literature

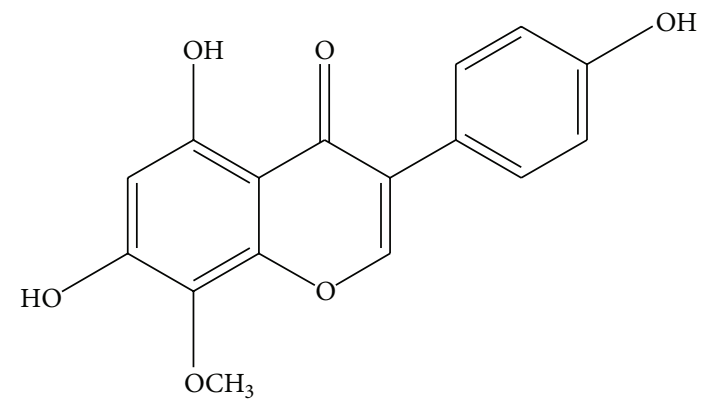

Figure 1: Chemical structure of tectorigenin.

[17]. The purity $(99.46 \%)$ of tectorigenin was determined by HPLC (Figure 1).

Tectorigenin. Pale yellow solid, (-)-ESI-MS m/z 299 [M-H] ${ }^{-}$, ${ }^{1} \mathrm{H}-\mathrm{NMR}$ (DMSO- $\left.d_{6}, 500 \mathrm{MHz}\right) \delta: 8.32(1 \mathrm{H}, \mathrm{s}, \mathrm{H}-2), 7.37(2 \mathrm{H}$, $\left.\mathrm{d}, J=8.7 \mathrm{~Hz}, \mathrm{H}-2^{\prime}, 6^{\prime}\right), 6.82\left(2 \mathrm{H}, \mathrm{d}, J=8.7 \mathrm{~Hz}, \mathrm{H}-3^{\prime}, 5^{\prime}\right)$, $6.49(1 \mathrm{H}, \mathrm{s}, \mathrm{H}-8), 3.74\left(3 \mathrm{H}, \mathrm{s}, \mathrm{OCH}_{3}\right) ;{ }^{13} \mathrm{C}-\mathrm{NMR}$ (DMSO-d $d_{6}$, $125 \mathrm{MHz}) \delta 181.1$ (C-4), 158.0 (C-9), 157.9 (C-4'), 154.6 (C-2), 153.8 (C-7), 153.3 (C-5), 131.9 (C-6), $130.7\left(\mathrm{C}-2^{\prime}, 6^{\prime}\right), 122.3$ (C-

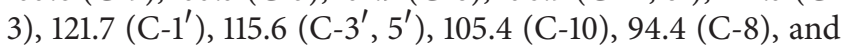
$60.5\left(\mathrm{OCH}_{3}\right)$.

2.2. Reagent. Ampicillin (AM), gentamicin (GT), ciprofloxacin (CP), Triton X-100 (TX-100), N,N'-dicyclohexylcarbodiimide (DCCD), and lipopolysaccharide (LPS) were purchased from Sigma-Aldrich Co. (St. Louis, USA). Mueller-Hinton broth (MHB) was purchased from Difco (Baltimore, MD, USA). Tris(hydroxymethyl) aminomethane (TRIS) was obtained from AMRESCO (San Francisco, CA). Sodium azide $\left(\mathrm{NaN}_{3}\right)$ and PGN were purchased from Fluka (Switzerland).

2.3. Bacterial Strains and Growth Conditions. Three clinical isolates of MRSA were obtained from three different patients at Wonkwang University Hospital (Iksan, South Korea). The other two strains were S. aureus ATCC 33591 (methicillinresistant strain) and S. aureus ATCC 25923 (methicillinsusceptible strain). Before use, all bacteria were stored in $30 \%$ glycerol and frozen at $-70^{\circ} \mathrm{C}$ and were cultured in MuellerHinton broth (MHB) and Mueller-Hinton agar (MHA) (Difco Laboratories, Baltimore, MD, USA) and incubated at $37^{\circ} \mathrm{C}$ for $24 \mathrm{~h}$ for each experiment.

2.4. Minimum Inhibitory Concentration. The minimum inhibitory concentration (MIC) was determined using the broth microdilution method according to the Clinical and Laboratory Standards Institute guideline (CLSI, 2006) [18]. TTR was diluted by MHB in 96-well plate $(0.5 \%[\mathrm{w} / \mathrm{v}]$ stock concentration). Preparation of the microorganism suspension was prepared by growing microorganism in broth for $24 \mathrm{~h}$, and the suspensions were adjusted to a $0.5 \mathrm{McFarland}$ standard turbidity (approximately $1.5 \times$ $10^{8} \mathrm{CFU} / \mathrm{mL}$ ). Final inoculums were adjusted to the $1.5 \times$ $10^{6} \mathrm{CFU} / \mathrm{mL}$. The plates were then incubated along with 
inoculum at $37^{\circ} \mathrm{C}$ for $18 \mathrm{~h}$. MIC was defined at the lowest concentration of antibiotics and TTR. At the end of each incubation period, the well plates were visually examined for turbidity. Cloudiness indicated that bacterial growth has not been inhibited by the concentration of antimicrobial agent in the medium.

2.5. Antibacterial Activity with Detergent or ATPase Inhibitors. To elucidate whether the antibacterial activity of TTR was associated with either the altered membrane permeability or the mechanism of multidrug resistance (MDR), we examined the antibacterial activity of TTR in the presence of detergents and ATPase-inhibiting agents, respectively. To determine the detergent-induced permeabilization, a particular concentration of TTR was determined using the detergent TX-100 [19]. The nonionic detergent TX-100 greatly increases antibiotic sensitivity [20]. DCCD and $\mathrm{NaN}_{3}$, a metabolic inhibitor that can decrease ATP levels by disrupting electrochemical proton gradients in a bacterial environment, were used as inhibitors of ATPase [21, 22]. The antibacterial activity of TTR was measured in the presence of $0.01 \%$ TX-100, $0.0015 \% \mathrm{NaN}_{3}$, and $6.25 \mu \mathrm{g} / \mathrm{mL}$ DCCD.

2.6. Effect of Exogenous Peptidoglycan on TTR Activity. To determine the activity of exogenous PGN in the presence of TTR, TTR+PGN combination assays were performed using the method by Zhao et al. [23]. This assay indicated whether TTR directly binds PGN and interrupted integrity of cell wall. TTR was added to PGN by serial dilution. LPS was used as a control.

\subsection{Transmission Electron Microscopy (TEM). MRSA} exponential-phase cultures were prepared by diluting cultures into MHB overnight, which was continued at $37^{\circ} \mathrm{C}$ until the cultures reached the midlogarithmic phase of growth. MHB-grown exponential-phase MRSA was treated with $1 / 2 \times$ MIC and $1 \times$ MIC of TTR for $30 \mathrm{~min}$. Following the treatment, $2 \mathrm{~mL}$ of the culture was collected by centrifugation at $10,000 \mathrm{~g}$ for $10 \mathrm{~min}$. After removal of the supernatant, pellets were fixed with modified Ki Woo Kim fixative [24]. Specimens were examined with an energyfiltering transmission electron microscope (LIBRA 120; Carl Zeiss, Oberkochen, Germany) at an accelerating voltage of $120 \mathrm{kV}$. Transmitted electron signals were recorded using a $4 \mathrm{k} \times 4 \mathrm{k}$ slow-scan charge-coupled device camera (Ultrascan 4000 SP; Gatan, Pleasanton, CA) attached to the electron microscope.

\section{Results}

3.1. The MICs of TTR. The MIC values of TTR against all strains were $125 \mu \mathrm{g} / \mathrm{mL}$. All strains were resistant to AM, GT, and CP with MIC ranging from 31.25 to $1,000 \mu \mathrm{g} / \mathrm{mL}$ (Table 1).

3.2. Antibacterial Activity with Detergent or ATPase Inhibitors. The increased effect of detergent-induced membrane permeability on the activity of TTR is shown in Figure 2. We
TABLE 1: MIC of S. aureus strains used in experiments.

\begin{tabular}{lccccc}
\hline \multirow{2}{*}{ S. aureus strains } & \multirow{2}{*}{ Class } & \multicolumn{4}{c}{ MIC $(\mu \mathrm{g} / \mathrm{mL})$} \\
& & TTR & AM & GT & CP \\
\hline ATCC 25923 & MSSA & 125 & 31.25 & 62.5 & 31.25 \\
ATCC 33591 & MRSA & 125 & 1,000 & 31.25 & 500 \\
DPS-1 & MRSA & 125 & 1,000 & 250 & 125 \\
DPS-2 & MRSA & 125 & 1,000 & 125 & 125 \\
DPS-3 & MRSA & 125 & 1,000 & 125 & 125 \\
\hline
\end{tabular}

TTR: tectorigenin; AM: ampicillin; GT: gentamicin; CP: ciprofloxacin; DPS: Staphylococcus aureus strains from the Department of Plastic Surgery, Wonkwang University Hospital.

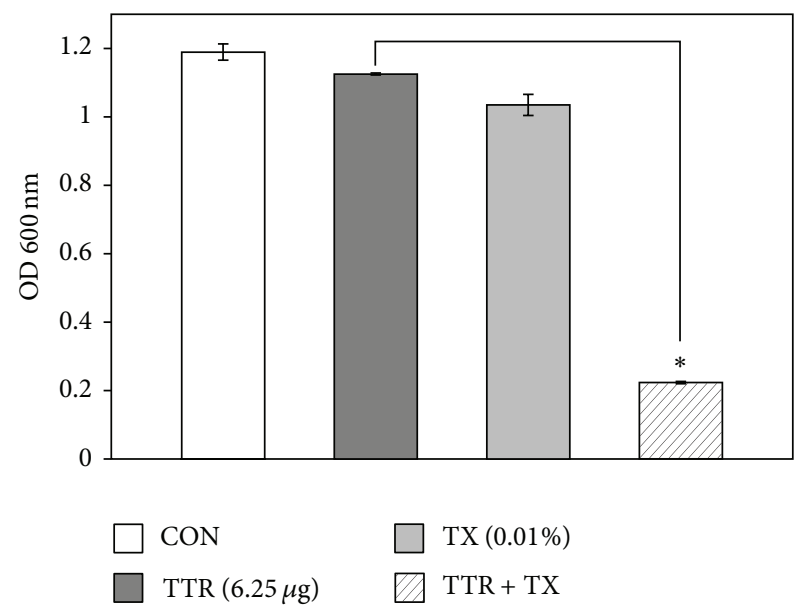

FIgURE 2: The effect of the membrane-permeabilizing agent Triton X-100 (TX-100) on the susceptibility of Staphylococcus aureus (ATCC 33591) to tectorigenin (TTR) treatment. The viability of bacteria was determined spectrophotometrically (optical density at $600 \mathrm{~nm}, \mathrm{OD}_{600}$ ) after incubation for $36 \mathrm{~h}$ with $6.25 \mu \mathrm{g} / \mathrm{mL}$ TTR and $0.01 \%$ Triton X-100. The data is represented as an average of three independent experiments. ${ }^{*} P<0.001$ as compared to TTR alone.

noted a modest reduction in the $\mathrm{OD}_{600}$ value of TTR-treated suspensions. Compared to the $\mathrm{OD}_{600}$ value of TTR alone $(6.25 \mu \mathrm{g} / \mathrm{mL})$, the $\mathrm{OD}_{600}$ value of suspensions treated with the combination of TX-100 and TTR was reduced to $80 \%$. Bacterial viability in the presence of TTR with DCCD and $\mathrm{NaN}_{3}$ as metabolic inhibitors had been reduced to $79 \%$ and $68 \%$, respectively, compared to that with TTR alone (Figures 3 and 4$)$

3.3. The Binding of TTR and Peptidoglycan (PGN) with TTR. The binding of TTR to PGN was confirmed by adding PGN $(0-125 \mu \mathrm{g} / \mathrm{mL})$ derived from $S$. aureus into MHB containing TTR alone $(62.5 \mu \mathrm{g} / \mathrm{mL})$. At a concentration of $125 \mu \mathrm{g} / \mathrm{mL}$, PGN inhibited the antibacterial activity of TTR, whereas LPS did not show any inhibitory effects (Figure 5).

3.4. TEM of MRSA. The control cells had normal morphology of $S$. aureus with distinct septa (Figure 6(a)). However, MRSA cells treated with TTR had decreased numbers of distorted septa (Figure 6(b)). Distinct septa formation was rarely observed in the treated cells. Ghost cells and decreased 


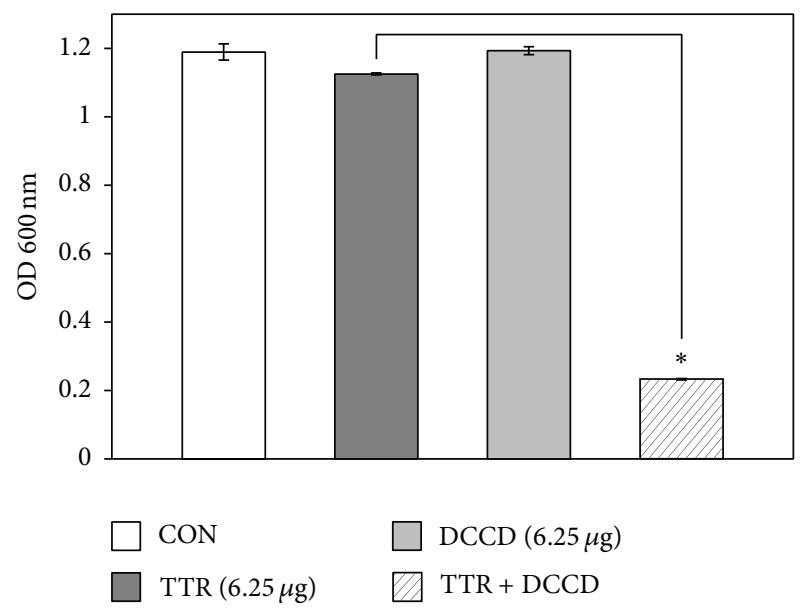

FIgure 3: The effect of the ATPase-inhibitor $N, N^{\prime}$ - dicyclohexylcarbodiimide (DCCD) on the susceptibility of Staphylococcus aureus (ATCC 33591) to tectorigenin (TTR) treatment. The viability of bacteria was determined spectrophotometrically (optical density at $\left.600 \mathrm{~nm}, \mathrm{OD}_{600}\right)$ after incubation for $36 \mathrm{~h}$ with $6.25 \mu \mathrm{g} / \mathrm{mL}$ TTR and $6.25 \mu \mathrm{g} / \mathrm{mL}$ DCCD. The data is represented as an average of three independent experiments. ${ }^{*} P<0.001$ as compared to TTR alone.

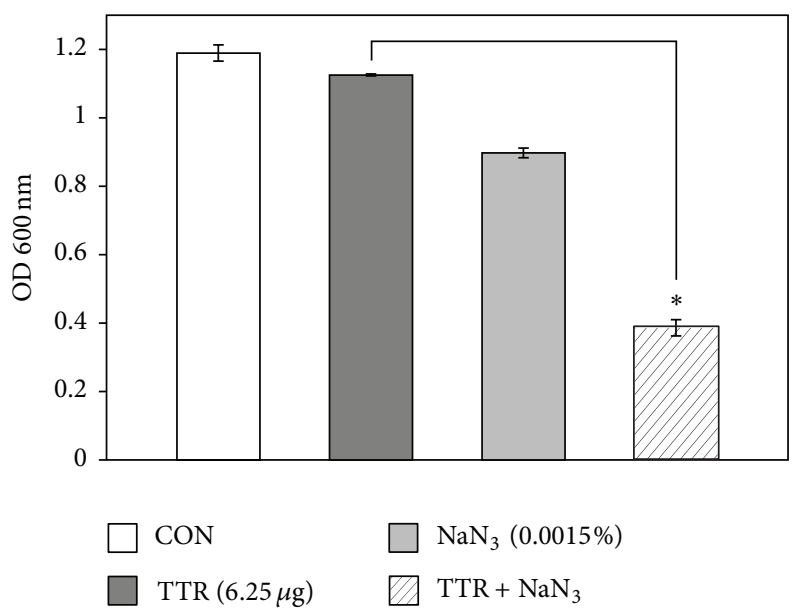

FIgURE 4: Effect of the ATPase-inhibitor $\mathrm{NaN}_{3}$ on the susceptibility of Staphylococcus aureus (ATCC 33591) to tectorigenin (TTR). The viability of bacteria was determined spectrophotometrically (optical density at $600 \mathrm{~nm}, \mathrm{OD}_{600}$ ) after incubation for $36 \mathrm{~h}$ with $12.5 \mu \mathrm{g} / \mathrm{mL}$ TTR and $0.0015 \% \mathrm{NaN}_{3}$. The data is average of three independent experiments. ${ }^{*} P<0.001$ as compared to TTR alone.

cell divisions were more frequently observed in TTR exposed cells (Figure 6(c)) compared to the control.

\section{Discussion}

Generally, antibacterial drugs inhibit bacterial growth in different targets, including inhibition of cell wall synthesis, disruption of cell membrane function, inhibition of protein, and nucleic acid synthesis [25]. According to our in vitro results, TTR showed the anti-MRSA action by increasing cytoplasmic membrane permeability and inhibiting adenosine triphosphatase (ATPase). MRSA (ATCC 33591) viability was highly decreased when TTR $(6.25 \mu \mathrm{g} / \mathrm{mL})$ and detergent TX-100 were used together. The nonionic detergent TX-100 helps to extract membrane protein [26]. TX-100 selectively solubilizes cytoplasmic membrane proteins and increase membrane permeability from strains. It reduces methicillin resistance and stimulates autolysis [27]. The cellular autolysin activity of TX-100 potentiated susceptibility to TTR in growth of MRSA. Growth of MRSA (ATCC 33591) in $0.01 \%$ TX100 alone had no effect on cell viability. This result suggests that TX-100 induces the release of autolysin inhibitor lipoteichoic acid (LTA) in the membrane bilayer. LTA is a major constituent of the gram-positive cell wall and is attached to the peptidoglycan layer. We also used $\mathrm{N}, \mathrm{N}$ dicyclohexylcarbodiimide (DCCD) and $\mathrm{NaN}_{3}$ as inhibitors of ATP synthase in the bacterial cells [21, 28]. DCCD disturbs $\mathrm{H}^{+}$-translocating sector $\left(\mathrm{F}_{0}\right)$ of the $\mathrm{F}_{0} \mathrm{~F}_{1}$-ATP synthase of coupling membranes. Most bacteria produce ABC (ATP-binding cassette) transporter that is an essential uptake system for amino acids in bacterial membrane [29]. These transporters cause the antibiotic resistant bacteria [30]. The antibacterial activity of TTR against MRSA in the presence of DCCD was markedly increased (Figure 3). The reason for increased susceptibility of MRSA toward TTR is the inhibition of ABC transporters that have ATP-dependent transporting activity by DCCD. $\mathrm{NaN}_{3}$ is a metabolic inhibitor, which reduces ATP level by disrupting electrochemical proton gradients in a bacterial cell [31,32]. Actually, it has been reported that $0.001 \% \mathrm{NaN}_{3}$ significantly increased susceptibility toward silybin in clinical Pseudomonas aeruginosa isolates [22].

Peptidoglycan (PGN) and lipoteichoic acid (LTA) are main components of gram-positive cell wall [33]. The cell wall of gram-positive bacteria including S. aureus consists of glycan layers, up to 30 sheets, and plays an essential role not only in osmotic protection but also in cell division. Cell envelope of $S$. aureus is surrounded by thick-layer of cross-linked peptidoglycan, whereas in gram-negative bacteria, the PGN layer is thin and is overlaid by an outer membrane composed mainly of lipopolysaccharide (LPS) [34-36]. As shown in Figure 5, TTR alone $(62.5 \mu \mathrm{g} / \mathrm{mL})$ greatly inhibited more than $50 \%$ of the growth of $S$. aureus, but PGN $(125 \mu \mathrm{g} / \mathrm{mL})$ from $S$. aureus blocked the antibacterial activity of TTR. These results indicate that direct binding with PGN and TTR completely blocked TTR-induced damage of the bacterial cell wall.

Transmission electron microscopy (TEM) can provide useful insight into the mechanism of action of antimicrobial agents. It is known that, when bacteria are exposed to antimicrobial agent at low concentrations, changes have been observed for bacterial morphology, ultrastructure, biochemistry, and multiplication rate [34]. Antibiotic treatment induces other cellular changes, such as cell lysis and separation of cytoplasmic contents from the membrane [25]. TEM images of MRSA confirmed that cytoplasmic membrane disruption and cell lysis of MRSA following exposure to the TTR. Thus, the mechanism of antibacterial activity of TTR involved the membrane disruption and cell lysis.

The overall results of the present study show that TTR has anti-MRSA activity. The results of TTR treatment in 


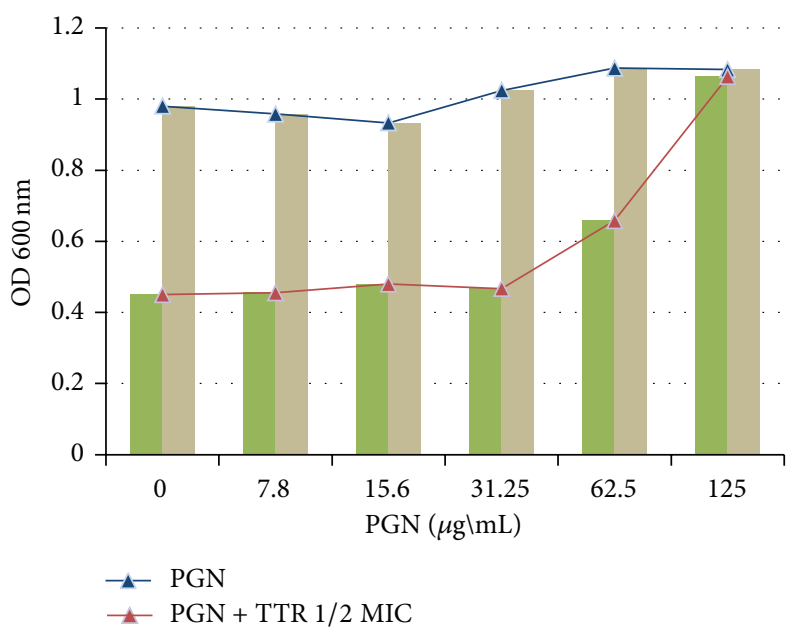

(a)

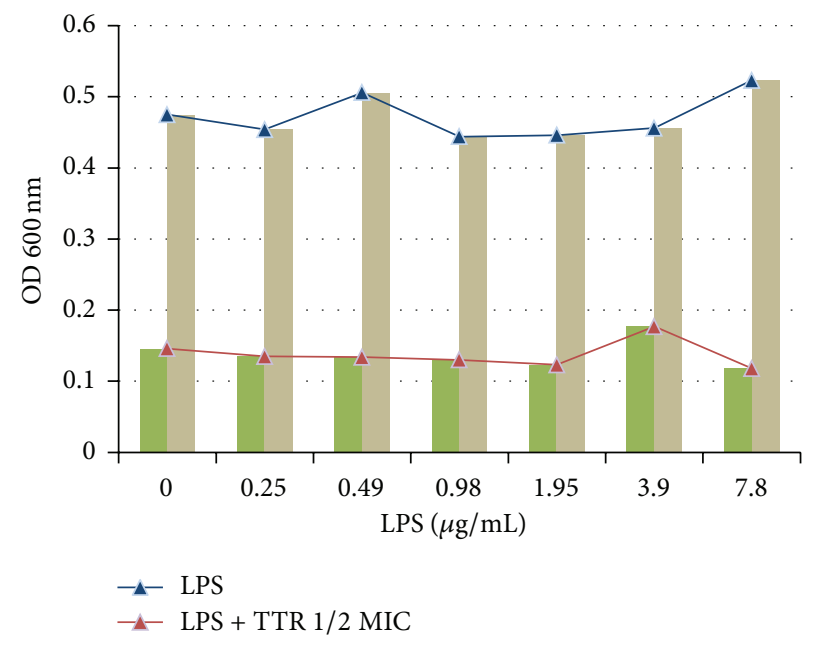

(b)

FIGURE 5: The binding effect of tectorigenin (TTR) with peptidoglycan (PGN) of the cell wall of Staphylococcus aureus (S. aureus). Lipopolysaccharide (LPS) was used as a control.

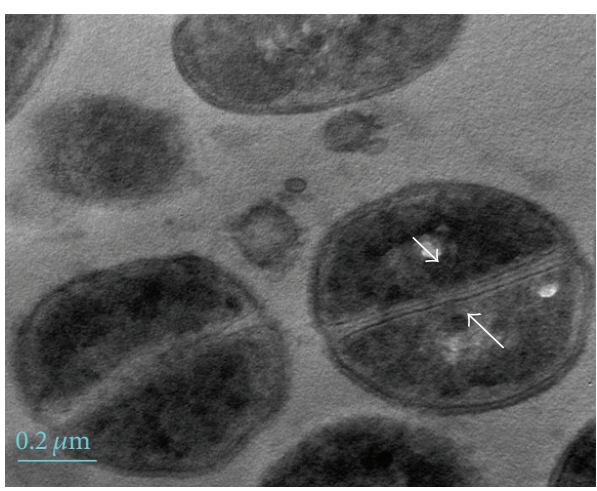

(a)

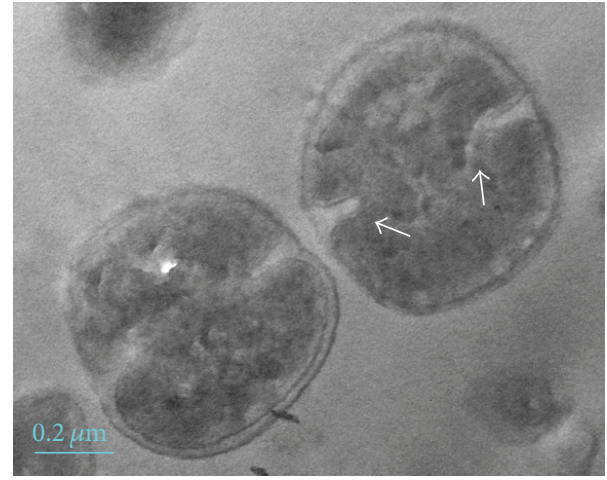

(b)

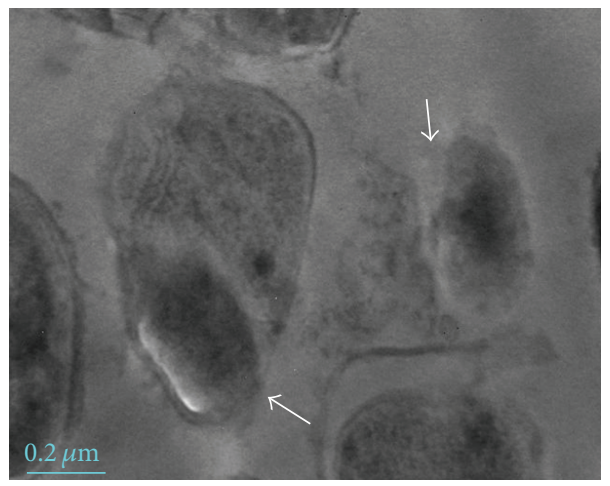

(c)

FIGURE 6: Transmission electron microscopy (TEM) images of methicillin-resistant Staphylococcus aureus (MRSA) (ATCC 33591) after 24 h of tectorigenin (TTR) treatment. (a) MRSA in the untreated control appeared to have intact membrane; (b) MRSA treatment with 1/2 MIC TTR $(62.5 \mu \mathrm{g} / \mathrm{mL})$ hampered membrane integrity and caused membrane damage; (c) MRSA treatment with MIC TTR (125 $\mu \mathrm{g} / \mathrm{mL})$ showed cytoplasmic membrane disruption and separated cell. 
combination with TX-100 or DCCD and $\mathrm{NaN}_{3}$ showed that TTR has role in increasing cytoplasmic membrane permeability and decreasing activity of $\mathrm{ABC}$ transporter. These results show the promising effect for the use of TTRbased products in the treatment of MRSA. Further, in vivo experiments are needed for the clinical use of TTR on MRSAinfected patients.

\section{Conflict of Interests}

The authors declare that there is no conflict of interests regarding the publication of this paper.

\section{Authors' Contribution}

Dae-Ki Joung and Su-Hyun Mun are contributed equally to this work.

\section{Acknowledgments}

This study was supported by the Grant of the Traditional Korean Medicine R\&D project, Ministry of Health \& Welfare (no. B120069), and by Basic Science Research Program through the National Research Foundation of Korea (NRF) funded by the Ministry of Education (2013060380), Republic of Korea; tectorigenin was kindly provided by Standardized Material Bank for New Botanical Drugs through Bio \& Medical Technology Development Program of the MEST, Korea.

\section{References}

[1] M. Whitby, M.-L. McLaws, and G. Berry, "Risk of death from methicillin-resistant Staphylococcus aureus bacteraemia: a meta-analysis," Medical Journal of Australia, vol. 175, no. 5, pp. 264-267, 2001.

[2] K. J. Bozic and M. D. Ries, "The impact of infection after total hip arthroplasty on hospital and surgeon resource utilization," Journal of Bone and Joint Surgery A, vol. 87, no. 8, pp. 1746-1751, 2005.

[3] E. Gracia, A. Fernández, P. Conchello et al., "Adherence of Staphylococcus aureus slime-producing strain variants to biomaterials used in orthopaedic surgery," International Orthopaedics, vol. 21, no. 1, pp. 46-51, 1997.

[4] K. Seghrouchni, C. van Delden, D. Dominguez et al., "Remission after treatment of osteoarticular infections due to Pseudomonas aeruginosa versus Staphylococcus aureus: a casecontrolled study," International Orthopaedics, vol. 36, no. 5, pp. 1065-1071, 2012.

[5] J. C. de Lucas-Villarrubia, M. Lopez-Franco, J. J. Granizo, J. C. de Lucas-Garcia, and E. Gomez-Barrena, "Strategy to control methicillin-resistant Staphylococcus aureus post-operative infection in orthopaedic surgery," International Orthopaedics, vol. 28, no. 1, pp. 16-20, 2004.

[6] F. Aqil, I. Ahmad, and M. Owais, "Evaluation of antimethicillin-resistant Staphylococcus aureus (MRSA) activity and synergy of some bioactive plant extracts," Biotechnology Journal, vol. 1, no. 10, pp. 1093-1102, 2006.

[7] T. Han, G. Cheng, Y. Liu, H. Yang, Y.-T. Hu, and W. Huang, "In vitro evaluation of tectoridin, tectorigenin and tectorigenin sodium sulfonate on antioxidant properties," Food and Chemical Toxicology, vol. 50, no. 2, pp. 409-414, 2012.

[8] C.-H. Pan, E. S. Kim, S. H. Jung, C. W. Nho, and J. K. Lee, "Tectorigenin inhibits IFN- $\gamma /$ LPS-induced inflammatory responses in murine macrophage RAW 264.7 cells," Archives of Pharmacal Research, vol. 31, no. 11, pp. 1447-1456, 2008.

[9] P. Thelen, J.-G. Scharf, P. Burfeind et al., "Tectorigenin and other phytochemicals extracted from leopard lily Belamcanda chinensis affect new and established targets for therapies in prostate cancer," Carcinogenesis, vol. 26, no. 8, pp. 1360-1367, 2005.

[10] D. Seidlová-Wuttke, O. Hesse, H. Jarry et al., "Belamcanda chinensis and the thereof purified tectorigenin have selective estrogen receptor modulator activities," Phytomedicine, vol. 11, no. 5, pp. 392-403, 2004.

[11] S. H. Jung, Y. S. Lee, S. Lee et al., "Anti-angiogenic and anti-tumor activities of isoflavonoids from the rhizomes of Belamcanda chinensis," Planta Medica, vol. 69, no. 7, pp. 617-622, 2003.

[12] E.-A. Bae and D.-H. Kim, "In vitro anti-Helicobacter pylori activity of irisolidone isolated from the flowers and rhizomes of Pueraria thunbergiana," Planta Medica, vol. 67, no. 2, pp. 161163, 2001.

[13] "Chinese-English Dictionary of Traditional Chinese Medicine," 1997.

[14] K.-T. Lee, I.-C. Sohn, Y.-K. Kim et al., "Tectorigenin, an isoflavone of Pueraria thunbergiana BENTH., induces differentiation and apoptosis in human promyelocytic leukemia HL-60 cells," Biological and Pharmaceutical Bulletin, vol. 24, no. 10, pp. 1117-1121, 2001.

[15] P. Thelen, J.-G. Scharf, P. Burfeind et al., "Tectorigenin and other phytochemicals extracted from leopard lily Belamcanda chinensis affect new and established targets for therapies in prostate cancer," Carcinogenesis, vol. 26, no. 8, pp. 1360-1367, 2005.

[16] L. Liu, W. Li, and Y. Gao, "Simultaneous determination of tectorigenin-7-O-xylosylglucosid, tectoridin and tectorigenin in flowers of Pueraria lobata by HPLC," Zhongguo Zhongyao Zazhi, vol. 35, no. 17, pp. 2308-2311, 2010.

[17] S. O. Lee, W. S. Woo, E. H. Woo et al., "Isoflavonoids of Belamcanda chinensis," Korean Journal of Pharmacognosy, vol. 20, pp. 219-222, 1989.

[18] "Clinical and Laboratory Standards Institute. Methods for dilution antimicrobial susceptibility tests for bacteria that grow aerobically," Approved Standards M7-A7, CLSI, Wayne, Pa, USA, 2006.

[19] S. J. Cordwell, M. R. Larsen, R. T. Cole, and B. J. Walsh, "Comparative proteomics of Stamphylococcus aureus and the response of methicillin-resistant and methicillin-sensitive strains to Triton X-100," Microbiology, vol. 148, no. 9, pp. 27652781, 2002.

[20] H. Shibata, H. Saito, C. Yomota, T. Kawanishi, and H. Okuda, "Alterations in the detergent-induced membrane permeability and solubilization of saturated phosphatidylcholine/cholesterol liposomes: effects of poly(ethylene glycol)-conjugated lipid," Chemical and Pharmaceutical Bulletin, vol. 60, no. 9, pp. 11051111, 2012.

[21] P. E. Linnett and R. B. Beechey, "Inhibitors of the ATP synthetase systems," Methods in Enzymology, vol. 55, pp. 472$518,1979$.

[22] H. J. Jung and D. G. Lee, "Synergistic antibacterial effect between silybin and N,N'- dicyclohexylcarbodiimide in clinical 
Pseudomonas aeruginosa isolates," Journal of Microbiology, vol. 46, no. 4, pp. 462-467, 2008.

[23] W.-H. Zhao, Z.-Q. Hu, S. Okubo, Y. Hara, and T. Shimamura, "Mechanism of synergy between epigallocatechin gallate and $\beta$-lactams against methicillin-resistant Staphylococcus aureus," Antimicrobial Agents and Chemotherapy, vol. 45, no. 5, pp. 17371742, 2001.

[24] K. W. Kim and E. W. Park, "Ultrastructure of spined conidia and hyphae of the rice false smut fungus Ustilaginoidea virens," Micron, vol. 38, no. 6, pp. 626-631, 2007.

[25] L. Drago, E. de Vecchi, L. Nicola, and M. R. Gismondo, "In vitro evaluation of antibiotics' combinations for empirical therapy of suspected methicillin resistant Staphylococcus aureus severe respiratory infections," BMC Infectious Diseases, vol. 7, article 111, 2007.

[26] D. Raychaudhuri and A. N. Chatterjee, "Use of resistant mutants to study the interaction of Triton X-100 with Staphylococcus aureus," Journal of Bacteriology, vol. 164, no. 3, pp. 1337-1349, 1985.

[27] H. Komatsuzawa, K. Ohta, M. Sugai et al., “Tn551-mediated insertional inactivation of the $\mathrm{fmtB}$ gene encoding a cell wallassociated protein abolishes methicillin resistance in Staphylococcus aureus," Journal of Antimicrobial Chemotherapy, vol. 45, no. 4, pp. 421-431, 2000.

[28] F. Zanotti, R. Casadio, C. Perrucci, and F. Guerrieri, "DCCDsensitive proton permeability of bacterial photosynthetic membranes. Cross-reconstitution studies with purified bovine heart F(o) subunits," Biochimica et Biophysica Acta, vol. 1276, no. 1, pp. 80-86, 1996.

[29] F. Fulyani, G. Schuurman-Wolters, A. Žagar, A. Guskov, D.J. Slotboom, and B. Poolman, "Functional diversity of tandem substrate-binding domains in $\mathrm{ABC}$ transporters from pathogenic bacteria," Structure, vol. 21, pp. 1879-1888, 2013.

[30] E. Steinfels, C. Orelle, J.-R. Fantino et al., "Characterization of $\mathrm{YvcC}$ (BmrA), a multidrug $\mathrm{ABC}$ transporter constitutively expressed in Bacillus subtilis," Biochemistry, vol. 43, no. 23, pp. 7491-7502, 2004.

[31] C. J. Swallow, S. Grinstein, and O. D. Rotstein, "A vacuolar type $\mathrm{H}^{+}$-ATPase regulates cytoplasmic $\mathrm{pH}$ in murine macrophages," Journal of Biological Chemistry, vol. 265, no. 13, pp. 7645-7654, 1990.

[32] P. P. Gonçalves, S. M. Meireles, P. Neves, and M. G. P. Vale, "Methods for analysis of $\mathrm{Ca}^{2+} / \mathrm{H}^{+}$antiport activity in synaptic vesicles isolated from sheep brain cortex," Brain Research Protocols, vol. 5, no. 1, pp. 102-108, 2000.

[33] J. C. Leemans, M. Heikens, K. P. M. van Kessel, S. Florquin, and T. van der Poll, "Lipoteichoic acid and peptidoglycan from Staphylococcus aureus synergistically induce neutrophil influx into the lungs of mice," Clinical and Diagnostic Laboratory Immunology, vol. 10, no. 5, pp. 950-953, 2003.

[34] A. Al-Habib, E. Al-Saleh, A.-M. Safer, and M. Afzal, "Bactericidal effect of grape seed extract on methicillin-resistant Staphylococcus aureus (MRSA)," Journal of Toxicological Sciences, vol. 35, no. 3, pp. 357-364, 2010.

[35] A. M. Farca, P. Nebbia, and G. Re, "Potentiation of antibiotic activity by EDTA-tromethamine against three clinically isolated gram-positive resistant bacteria. An in vitro investigation," Veterinary Research Communications, vol. 18, no. 1, pp. 1-6, 1994.

[36] V. Lorian and B. Atkinson, "Effect of serum on gram-positive cocci grown in the presence of penicillin," Journal of Infectious Diseases, vol. 138, no. 6, pp. 865-871, 1978. 


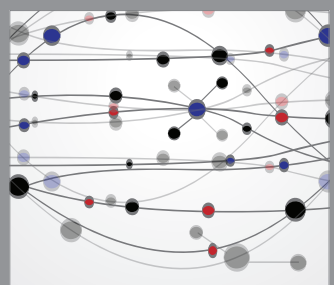

The Scientific World Journal
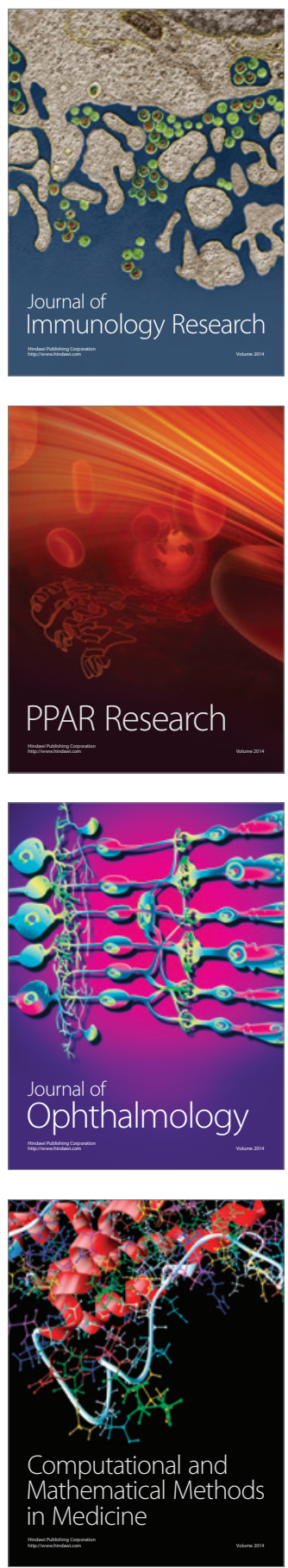

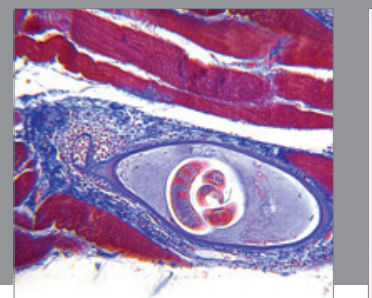

Gastroenterology

Research and Practice
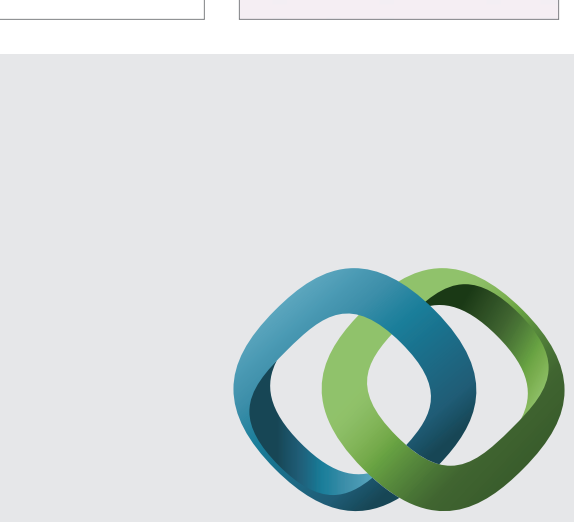

\section{Hindawi}

Submit your manuscripts at

http://www.hindawi.com
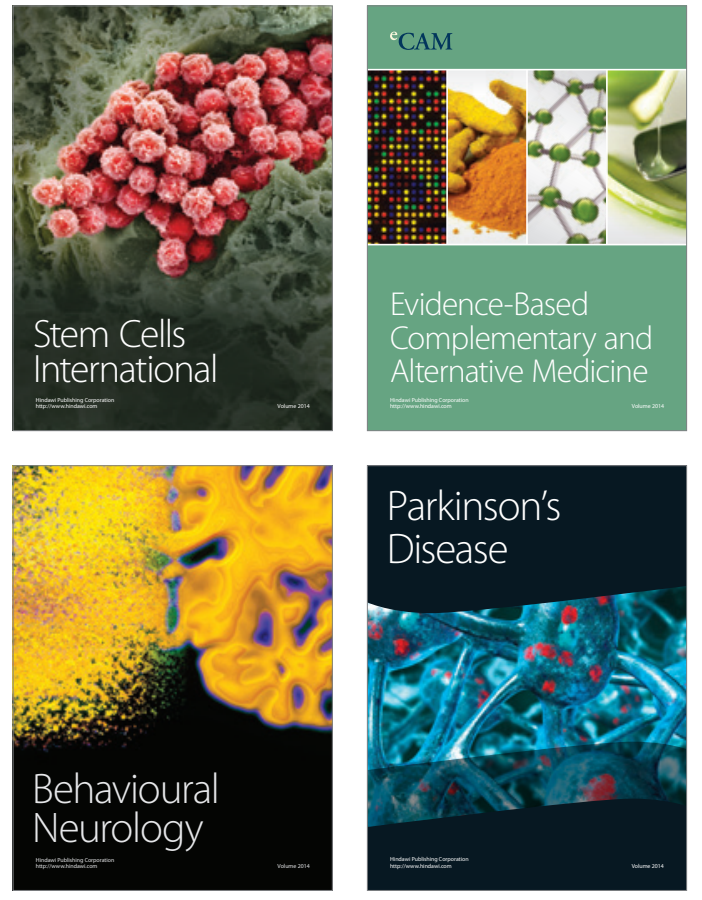
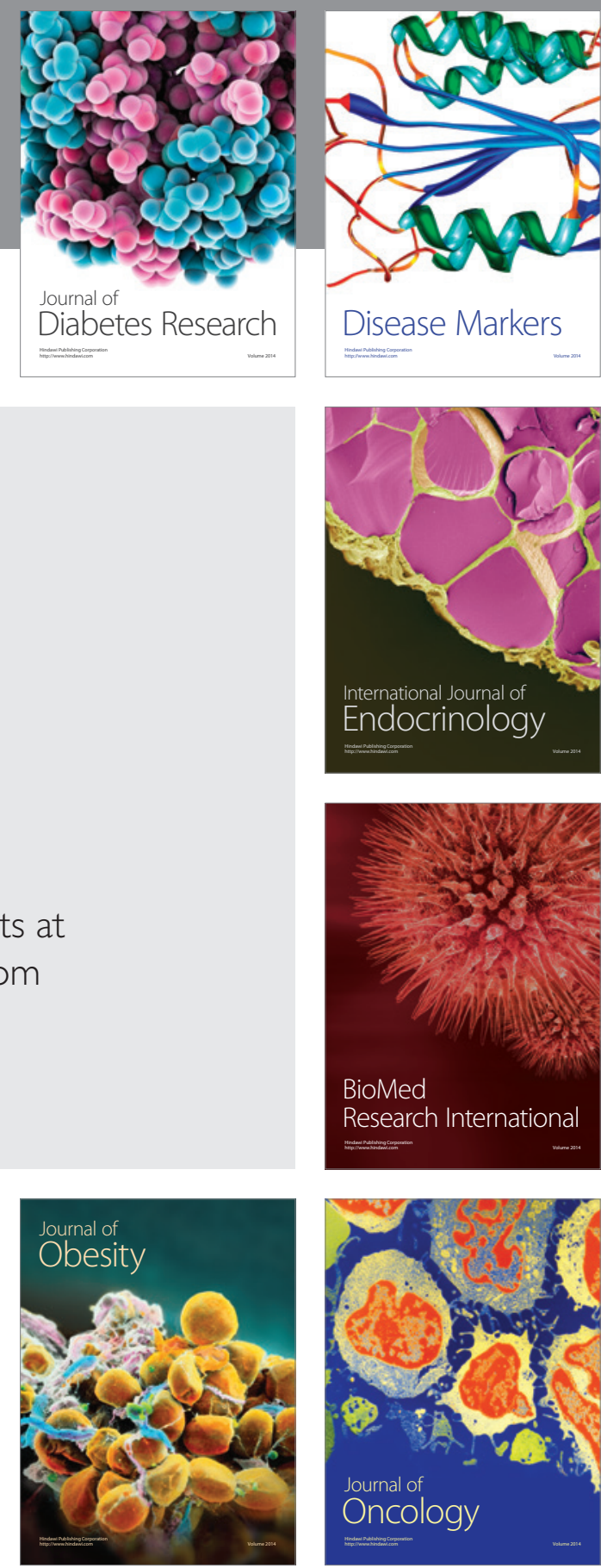

Disease Markers
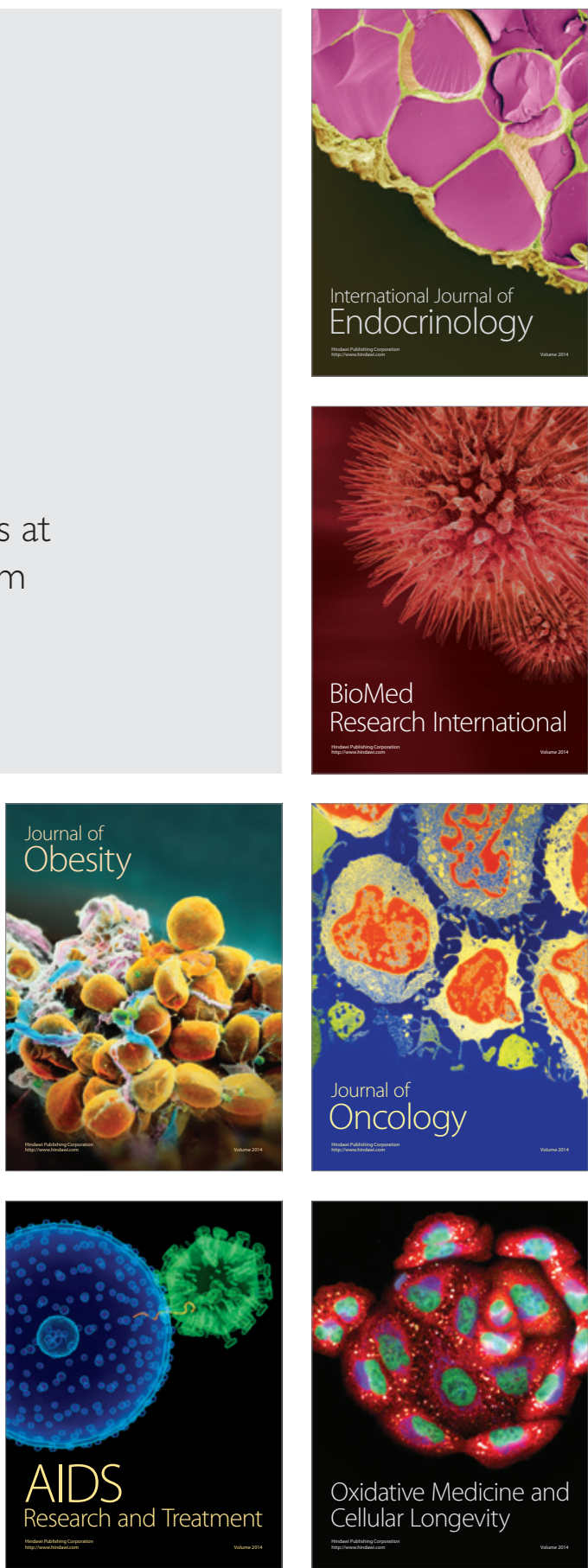